\title{
Unknown syndrome: ischiadic hypoplasia, renal dysfunction, immunodeficiency, and a pattern of minor congenital anomalies
}

\author{
C Braegger, A Bottani, Françoise Hallé, A Giedion, E Leumann, R Seger, U Willi, A Schinzel
}

\begin{abstract}
We report a 6 year old male with a pattern of malformations and anomalies including intrauterine growth retardation, microcephaly, psychomotor retardation, a pattern of craniofacial anomalies (flat face, hypertelorism, epicanthic folds, strabismus, short nose, low set ears), hypospadias and cryptorchidism, bilateral partial cutaneous syndactyly between fingers 2 to 5 and toes 2 to 4 , postaxial polydactyly of the fingers and toes, severe conductive hearing loss, hypoplasia of the ischiadic bones, complex renal dysfunction, hypogammaglobulinaemia with proneness to bacterial infections of the upper and lower respiratory tract, and recurrent pseudomembranous enterocolitis. The parents are cousins of Turkish origin.
\end{abstract}

\section{Case report}

The proband, a 5 year old male, was the first child of a 17 year old mother and her 19 year old cousin, both of Turkish origin. The mother had premature contractions during the second trimester. Spontaneous vaginal delivery occurred in the 38th week of pregnancy. Birth weight was $1960 \mathrm{~g}$, length $44 \mathrm{~cm}$, and head circumference $30.6 \mathrm{~cm}$ (all <3rd centile).

Department of Paediatrics, University of Zürich, Switzerland.

C Braegger, F Hallé, A Giedion, E Leumann, R Seger, U Willi

Institut für Medizinische Genetik der Universität Zürich, Rämistrasse 74, 8001 Zürich, Switzerland.

A Bottani, A Schinzel

Correspondence to Professor Schinzel.

Received for publication 14 April 1990 Accepted for publication 22 June 1990
COURSE

During his first 3 years, he suffered from recurrent bacterial infections of the upper and lower respiratory tract with recurrent otitis media, tonsillitis, sinusitis, bronchitis, and pneumonia. At the age of 4 years, intravenous immunoglobulin substitution at a dose of $0.4 \mathrm{~g} / \mathrm{kg}$ every four weeks was started. With this measure, and supplementary prophylactic cotrimoxazole (Bactrim, $36 \mathrm{mg} / \mathrm{kg} /$ day), the frequency of bacterial infections of the respiratory tract decreased markedly.

Between 4 and 6 years of age, the patient had four episodes of severe diarrhoea with fever and abdominal pain, each following antibiotic treatment for respiratory infection. The diarrhoea was caused by toxin producing Clostridium difficile and responded well to vancomycin or ornidazole. At the age of 4 years, bilateral severe conductive hearing loss was detected. His psychomotor development was markedly delayed, but his growth was normal.

CLINICAL EXAMINATION (FIGS 1 AND 2)

At the age of 7 years, length was $117.5 \mathrm{~cm}$ (3rd to 10 th centile), weight was $23.0 \mathrm{~kg}$ ( 50 th centile), and head circumference was $53 \mathrm{~cm}$ (50th to 75th centile). He displayed the following major and minor anomalies: a flat occiput and a prominent forehead with high anterior hair line, shallow supraorbital ridges, deep set eyes with slight inner epicanthic folds, an ICD of $2.8 \mathrm{~cm}$ (25th centile) and OCD of $8.5 \mathrm{~cm}$ (75th centile), alternating esotropia, horizontal palpebral fissures, a short nose with upturned, bulbous tip and short columella, narrow nares, a short philtrum, very carious teeth, and posteriorly rotated ears with hypoplastic helices and prominent anthelices. He had second degree hypospadias, a hypoplastic scrotum, and bilateral cryptorchidism. He had a hand length of $12.7 \mathrm{~cm}$ and middle finger length of $5.1 \mathrm{~cm}$ (both $3 \mathrm{rd}$ centile), clinodactyly and short middle phalanges of the little fingers with only one flexion crease, tapering fingers, bilateral appendages from removed sixth 


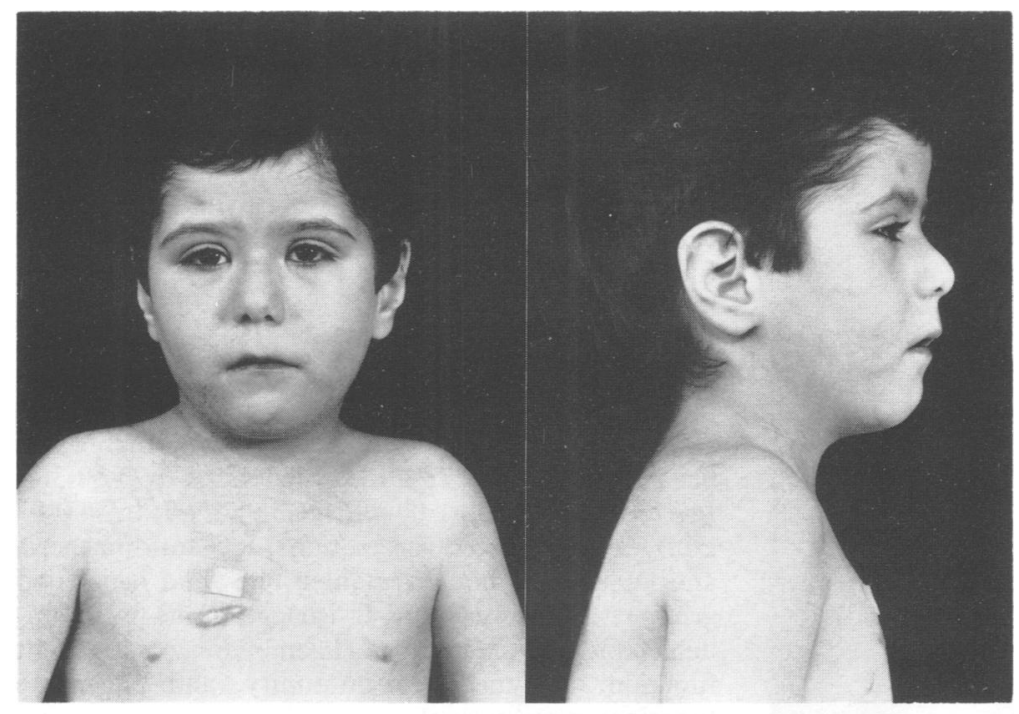

Figure 1 The patient at 6 years 3 months.

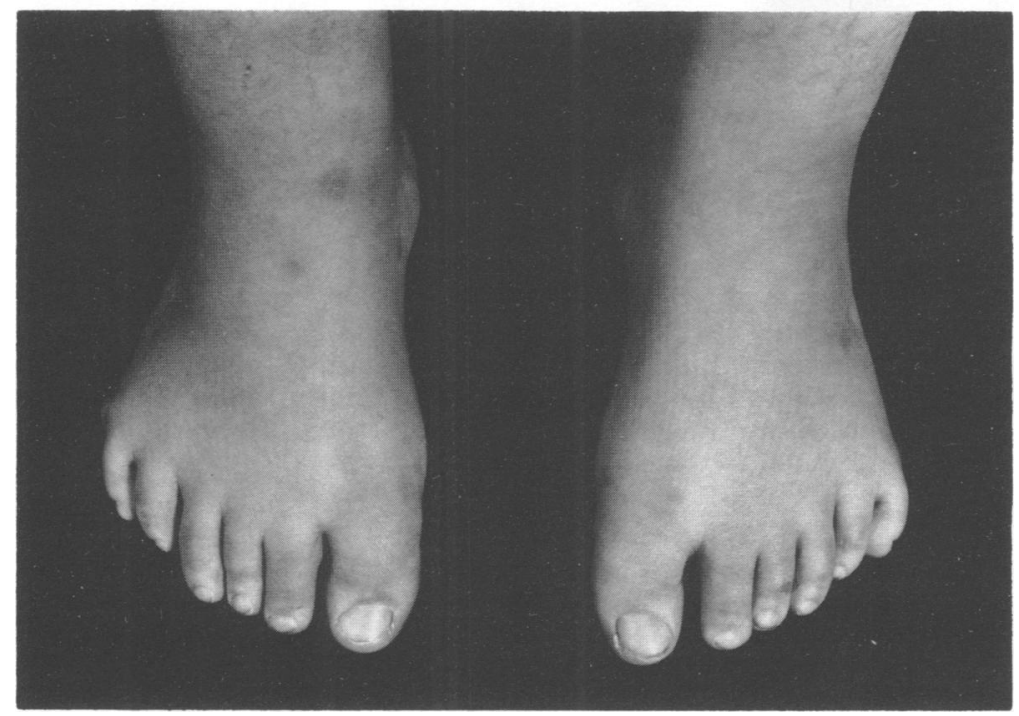

Figure 2 Both feet of the patient showing postaxial polydactyly and abnormal big toenails.

fingers on the base of the ulnar side of the fifth proximal phalanges, no simian creases, 10 whorls on the fingertips, and very mild cutaneous syndactyly between fingers 2 to 5 . There were flat arches of the feet, complete sixth rays of the toes, clinodactyly of the halluces and fourth toes, appendages on the base of the fibular side of the sixth toes (indicating heptadactyly), bilateral $1 / 3$ cutaneous syndactyly between toes 2 and 3, and hypoplastic toenails. There was hypertrichosis over the back and extremities. Muscle tone was decreased, and finger and toe joints were hyperextensible. The remainder of the physical examination was normal.
INVESTIGATIONS (FIGS 3 AND 4)

Radiographs showed bilateral absence of the ischiadic ramus and tuberosity; postaxial polydactyly of both feet with Y shaped fifth metartarsals; small bony fragments lateral to the fifth metacarpal epiphyses; moderate flaring of the distal femoral metaphyses; moderately retarded bone age ( 2 years 8 months at $3 \frac{1}{2}$ years and $31 / 2$ years at 5 years 8 months); and small patellae. At the age of 10 days, renal ultrasonography showed large ( $5 \mathrm{~cm}$ in length) hyperechogenic kidneys with absence of corticomedullary differentiation and calyceal ectasia. The ultrasonographic appearance was consistent with polycystic renal disease, 


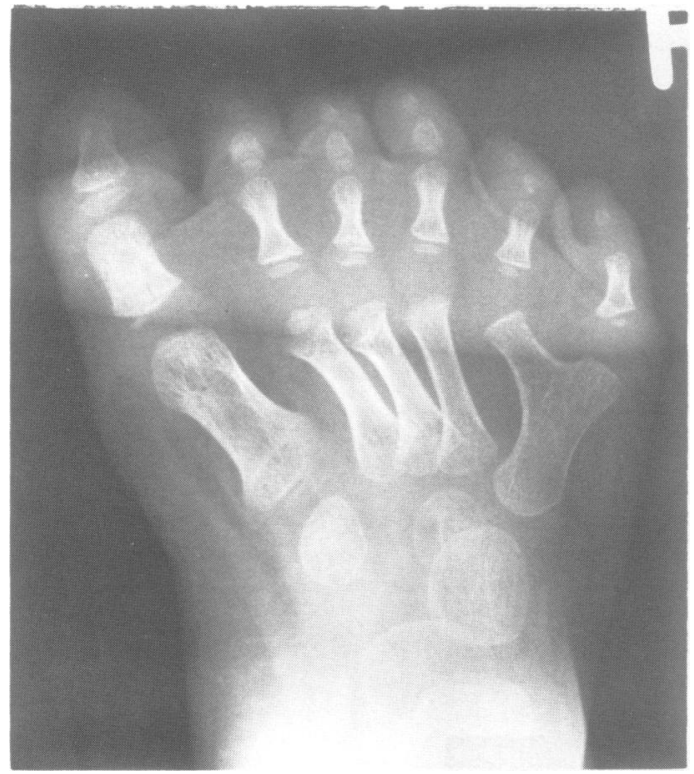

Figure 3 Right forefoot at 3 years 7 months showing postaxial polydactyly with $Y$ shaped metatarsal $V$.

although an extretory urogram failed to show tubular ectasia; however, it excluded obstructive uropathy.

At 6 years of age, the renal length was $6 \mathrm{~cm}$ (below normal length), and there was mild to moderate hyperechogenicity and moderate pelvicalyceal ectasia.

Glomerular function was significantly impaired with serum creatinine $100 \mu \mathrm{mol} / 1$ (normal for age $<60$ ). In addition, there was evidence of proximal tubular dysfunction with hypokalaemia (potassium $3.3 \mathrm{mmol} / \mathrm{l}$ ), mild metabolic acidosis (base excess $-4.8 \mathrm{mmol} / \mathrm{l}$ ), hypouricaemia (136 $\mu \mathrm{mol} / \mathrm{l})$, and generalised aminoaciduria, renal glycosuria $(1 \cdot 22 \mathrm{~g} / \mathrm{l})$, mild proteinuria $(2+)$, and a low threshold for phosphate excretion $(T P / G F R=1.5 \mathrm{mmol} / 1$, normal value $1 \cdot 5 \pm 0 \cdot 2$ ). Relative density of the urine was fixed between 1005 and 1008. There was slight hypercalciuria $(1.4 \mathrm{mmol} / \mathrm{l})$. Permission for renal biopsy was not given.

Antibody function tests showed panhypogammaglobulinaemia with an IgG level of $2.8 \mathrm{~g} / 1$ (normal value $6 \cdot 1 \pm 1 \cdot 5$ ); IgA undetectable (normal value $0.57 \pm 0.13$ ); IgM $0.23 \mathrm{~g} / \mathrm{l}$ (normal value $0.93 \pm 0.36$ ); IgG1 1.09 g/l; IgG2 1.00 g/l; IgG3 0.70 g/l; IgG4 0.07 g/l. Despite repeated vaccinations, IgG antidiphtheria antibodies were not detectable. The child had blood group A; however, anti-B isoagglutinins were undetectable. Evaluation of haemolytic complement function, cell mediated immunity, and phagocyte functions were normal.

\section{Discussion}

The combination of intrauterine growth retardation, minor craniofacial anomalies including short nose and epicanthic folds, postaxial polydactyly, hypospadias, excess of whorls on the fingertips, $2 / 3$ syndactyly of the toes, and mental retardation is characteristic of the Smith-Lemli-Opitz syndrome. ${ }^{1-3}$ Parental consanguinity also fits with the autosomal recessive inheritance of this syndrome. However, our patient has additional striking skeletal abnormalities and renal and immunological features which have not

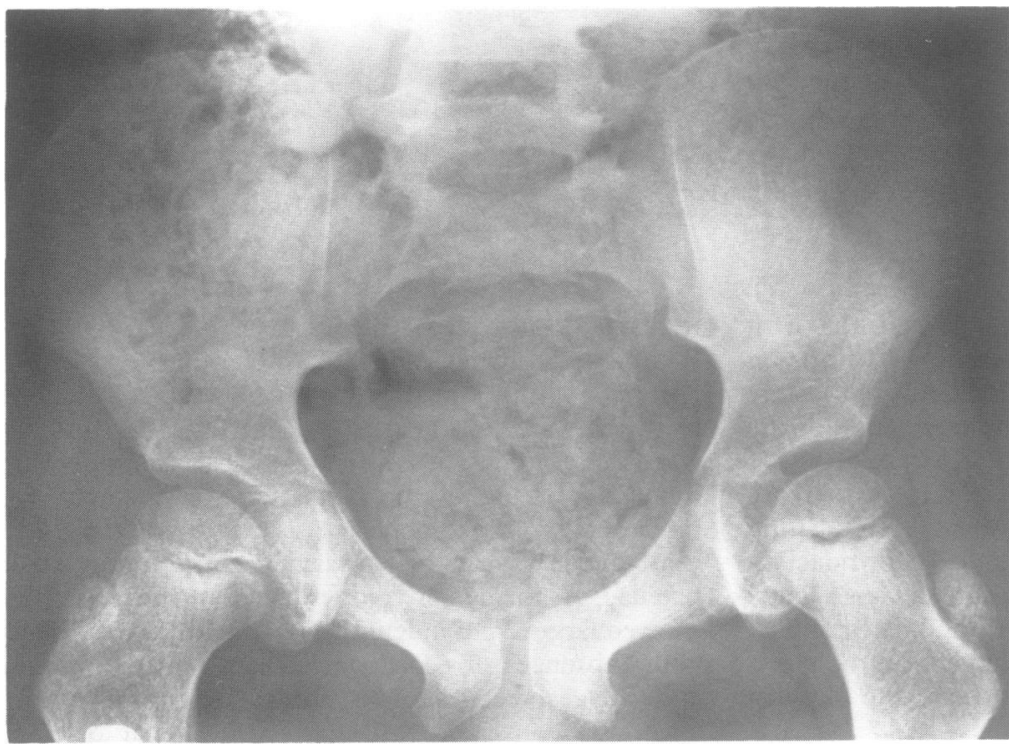

Figure 4 Pelvic radiographs at 6 years 7 months. The rami of the pubic bones are missing, but the acetabula are present. 
been observed so far in patients with the SmithLemli-Opitz syndrome.

Severe ischiadic hypoplasia is seen in the autosomal dominantly inherited small patellae syndrome. ${ }^{45}$ The patellae of our patient, however, are only moderately small, corresponding in size to the retarded bone age.

Parental consanguinity in our family points towards an autosomal recessive condition in the proband. This might be a 'new', that is, hitherto unreported, syndrome. Less likely, the patient might represent an extreme variant of the Smith-Lemli-Opitz syndrome. Finally, he could be homozygous for more than one deleterious recessive gene, so that his findings could be the result of a combination of more than one recessive condition.

1 Smith DW, Lemli L, Opitz JM. A newly recognized syndrome of multiple congenital anomalies. 7 Pediatr 1964;64:210-7.

2 Cherstvoy ED, Lazjuk GI, Luric IW, Nedzved MK, Usoev SS The pathological anatomy of the Smith-Lemli-Opitz syndrome. Clin Genet 1975;7:382-7.

3 Joseph DB, Uehling DT, Gilbert E, Laxova R. Genitourinary abnormalities associated with the Smith-Lemli-Opitz syndrome. f Urol 1987;137:719-21.

4 Scott JE, Taor WS. The small patella syndrome. $\mathcal{f}$ Bone foint Surg [Br] 1979;61:172-5.

5 Burckhardt A. Eine Kombination von Knie- und Beckendysplasie. (The small patella syndrome.) $Z$ Orthop 1988;126:22-9. 